\title{
AVALIAÇÃO DO PADRÃO LESIONAL DE CÃES das raças Ihasa apso, yorkshire terrier, shih-tzu e pug acometidos por dermatite atópica
}

\author{
Evaluation of the lesional pattern of dogs of the breeds \\ Ihasa apso, yorkshire terrier, shih-tzu and pug affected \\ by atopic dermatitis
}

\author{
Ana Carolina Aparecida Fernandes ${ }^{1 \star} \mathbb{D}^{\text {; }}$ Paulo Sergio Salzo²; Bruna de Paiva Fernandes ${ }^{3}$ \\ *Autor Correspondente: Ana Carolina Aparecida Fernandes. Rua Naochiti Tanaka, 235, Vila \\ Nogueira, Diadema, São Paulo, SP, Brasil, CEP 09951-190. \\ E-mail: ana97.carolfernandes@gmail.com
}

\begin{abstract}
Como citar: FERNANDES, Ana Carolina Aparecida; SALZO, Paulo Sergio; FERNANDES, Bruna de Paiva. Avaliação do padrão lesional de cães das raças Ihasa apso, yorkshire terrier, shih-tzu e pug acometidos por dermatite atópica. Revista de Educação Continuada em Medicina Veterinária e Zootecnia do CRMV-SP, São Paulo, v.19, n. 1, 2021. e38053. Doi 10.36440/recmvz.v19i1.38053

Cite as: FERNANDES, Ana Carolina Aparecida; SALZO, Paulo Sergio; FERNANDES, Bruna de Paiva. Evaluation of the lesional pattern of dogs of the breeds Ihasa apso, yorkshire terrier, shih-tzu and pug affected by atopic dermatitis. Journal of Continuing Education in Veterinary Medicine and Animal Science of CRMV-SP, São Paulo, v.19, n.1, 2021. e38053. Doi 10.36440/recmvz.v19i1.38053
\end{abstract}

\section{Resumo}

A Dermatite Atópica Canina (DAC) é uma doença multifacetada de caráter genético, em que o paciente apresenta uma resposta imune desregulada. Foram analisados o padrão lesional e de prurido em cães das raças Ihasa apso, yorkshire terrier, shih-tzu e pug de ambos os sexos, já diagnosticados anteriormente com DA, atendidos entre janeiro de 2017 e abril de 2019, no Hospital Veterinário da Universidade Metodista de São Paulo (Umesp), com o intuito de verificar um possível padrão lesional mais peculiar para cada raça, resultando em Ihasa apso com maior acometimento de falanges e interdigitos e menor em tronco, yorkshire terrier com maior insulto em orelhas e menor em região perianal, shih-tzu tendo maior acometimento de falanges e interdigitos e menor em abdomen, e o pug com maior injúria de falanges e interdigitos, e menor em região cefálica. Conclui-se que, ao se comparar a localização versus a incidência de lesões cutâneas em cães atópicos das raças estudadas, não houve grande diferença em termos de distribuição lesional.

Palavras-chave: Dermatite atópica. Cães. Padrão fenotípico.

1 Médica-veterinária, docente da Universidade Metodista de São Paulo (Umesp), São Paulo, SP, Brasil

2 Médico-veterinário, docente da Universidade Metodista de São Paulo (Umesp), São Paulo, SP, Brasil

3 Graduanda em Medicina Veterinária da Universidade Metodista de São Paulo (Umesp), São Paulo, SP, Brasil 


\section{Abstract}

Canine Atopic Dermatitis (CAD) is a multifaceted genetic disease, in which the patient has an exacerbated immune response. The lesion and pruritus pattern was analyzed in dogs of the lhasa apso, yorkshire terrier, shih-tzu and pug breeds of both sexes, previously diagnosed with AD, attended between January 2017 to April 2019 at the Veterinary Hospital of the Universidade Metodista de São Paulo (Umesp), with in order to verify a more peculiar lesion pattern for each breed, resulting in Ihasa apso with greater involvement of phalanges and interdigites and smaller in trunk, yorkshire terrier with greater insult in ears and less in perianal region, shih-tzu resulting in greater involvement of phalanges and interdigites and minor in the abdomen, and pug with greater injury of phalanges and interdigites and minor in the head. It is concluded that when comparing the incidence of skin lesions in atopic dogs of the studied breeds, there was no great difference in terms of lesional distribution.

Keywords: Atopic dermatitis. Dogs. Phenotypic pattern.

\section{Introdução e Revisão}

A DAC é a segunda morbidade de maior ocorrência dentre as dermatopatias pruriginosas crônicas que acometem os cães, alcançando 15\% dentre os caninos, e segundo estudos americanos, a DAC representa 30\% dos atendimentos de dermatopatias (MILLER; GRIFFIN; CAMPBELL, 2013), sendo menos frequente apenas que a dermatite alérgica à picada de pulgas (DAPP) (WHITE, 1998; HALLIWEL, 2006). Apresenta alterações gênicas relacionadas (HALLIWELL, 2006) à formação IgE (SCOTT; MiLLER; GRIFFIN, 1996; OLIVRY; HILL, 2001) e sensibilização alérgica, mediadores associados à inflamação e imunidade, a barreira cutânea, reparação de dano oxidativo, regulação do ciclo celular e apoptose (WOOD et al. 2010) em que o fenótipo clínico pode ser influenciado por inúmeros fatores, incluindo a herança genética do animal, o modo de vida, o ambiente, a natureza dos antígenos ofensores e fatores de risco (OLIVRY; HILL, 2001; ALVES et al., 2018).

Por sua complexa etiopatogenia, que inclui a diversidade de apresentação clínica, a qual depende de fatores genéticos, extensão das lesões, estágio da doença, a presença de infecções microbianas secundárias ou outros fatores, a DAC representa grande desafio aos clínicos veterinários e pesquisadores no que se refere ao tratamento e controle da enfermidade (WOOD et al., 2009). É importante ressaltar que a DAC não tem manifestações clínicas patognomônicas (FAVROT, 2009) que permitam um diagnóstico definitivo no momento da anamnese realizada com proprietário e ao exame físico do animal. Mormente, as áreas mais afetadas costumam ser condutos auditivos e pavilhões auriculares, face (especialmente as regiões perioculares, perilabiais, mentonianas e o plano nasolabial) axilas, abdômen, virilhas (OLIVRY; HILL, 2001), porção distal dos membros (superfícies dorso-digitais e interdigitais dorsal e ventral), áreas flexurais (flexuras carpianas, tíbio-társicas, as flexuras antecubitais e as flexuras poplíteas) e região perineal (SCOTT; MILLER; GRIFFIN, 1996, 2001).

Os cães com dermatite atópica podem apresentar a pele eritematosa, alopécica e disqueratótica, caracterizada por liquenificação, xerose e descamação, tanto por consequência do autotrauma provocado pelo prurido, como por infecções bacterianas ou fúngicas secundárias.

O prurido alesional ou sine materia pode ser a manifestação clínica inicial da doença e otites de repetição também compõem o histórico dos pacientes (GRIFFIN, 2001; HILLIER, DEBOER; 2001). É esperado que o grau de gravidade dessas alterações aumente com a exposição crônica aos fatores extrínsecos que precipitam ou intensificam a doença (ALVES et al., 2018). O prurido, manifestação cardeal da DAC, é classicamente definido tanto em humanos quanto em animais como uma sensação desagradável e irritante que provoca o desejo de coçar. O comportamento do prurido pode ser facilmente percebido pelos proprietários dos animais acometidos, os quais podem se arranhar, mordiscar, lamber ou friccionar partes do corpo contra objetos. Outras alterações no comportamento podem ser observadas, incluindo diminuição do apetite ou sono, e consequente diminuição da qualidade de vida desses animais (GRIFFIN; DEBOER, 2001; HILLIER, 2001). Por essa razão, é indispensável, 
durante a anamnese, a avaliação da intensidade do prurido, tanto para o auxílio diagnóstico quanto para o acompanhamento da evolução do tratamento (CHREN et al., 1996).

A gravidade do prurido é de difícil mensuração e, por vezes, pode se tornar subjetiva. Dessa forma, faz-se necessário o uso de recursos que permitem a avaliação do prurido, como as escalas que reúnem dados do comportamento do cotidiano dos animais de forma explicativa, os quais são reconhecidos e indicados por seus proprietários. A escala aborda características do comportamento que podem estar comprometidas com a manifestação do prurido, como dormir, comer, brincar e fazer exercícios, separando-as em prurido leve com episódios ocasionais, leve com episódios pouco frequentes, moderado com episódios regulares, grave com episódios prolongados e prurido extremamente grave quase que contínuo (MAJESKI et al, 2007).

O prurido pode ser classificado como agudo ou crônico e várias condições dermatológicas, e menos frequentemente não dermatológicas, podem ser responsáveis por desencadear prurido em cães, sendo a alergia uma das causas base mais comuns (BILSBOROUGH et al, 2006). Dentre as causas de prurido estão as doenças primárias, que desencadeiam prurido diretamente, e as secundárias, quando ocorrem como consequência a um dano à pele causado por uma doença primária. Lesões dermatológicas como pápulas, escoriações, erosões, úlceras, alopecia auto induzida e liquenificação se desenvolvem no curso da doença e, nesses casos, são consideradas secundárias à sensação de coceira (FAVROT et al. 2010).

O eritema associado à inflamação e prurido transcorre comumente com lesões secundárias ou autoinflingidas tais como escoriações e alopecia. Pápulas, pústulas, crostas e erosões são sintomas de infecção bacteriana secundária; a lignificação, hiperpigmentação e hiperplasia surgem concomitantemente com a colonização de Malassezia sp (FAVROT, 2009).

A predisposição racial pode ser variável, dependendo da localização geográfica (NODTVEDT, 2006) incidindo mais em raças puras (SOUZA; MARSELLA, 2001), sendo mais descrita nas raças boxer, chihuahua, yorkshire terrier, sharpei chinês, cairn terrier, west highland white terrier, scotish terrier, Ihasa apso, shih-tzu, fox terrier de pêlo duro, dálmata, pug, setter, boston terrier, golden retriever, labrador retriever, cocker spaniel, beagle, poodle, schnauzer miniatura, tervuren belga, shiba inus e beauceron (FARIAS, 2007; SCOTT; MILLER, 2001).

Não há dados consistentes, até o momento, sobre a predisposição sexual da DAC (WILHEM; KOVALIK; FAVROT, 2011). 0 início dos sintomas se dá entre seis e trinta e seis meses de idade (OLIVRY et al.2010). Entre 70\% e 78\% dos cães diagnosticados com DAC iniciam o quadro antes de completar três anos de idade (FAVROT, 2009; SCOTT; MILLER; et al. 2001).

0 estrato córneo é o principal segmento responsável por prevenir a passagem de alérgenos, patógenos e substâncias irritantes através da epiderme. Quando há alterações estruturais ou diminuição de lipídios e proteínas específicas (WHITE, M.I; JENKINSON, D. M.; LLOYD, D. H., 1987) ocorre inflamação cutânea, levando à diminuição de secreção de proteínas e agravando a disfunção da barreira, inclusive quando há constante contato com alérgenos. A pele não lesionada de cães atópicos não é idêntica à pele de cães saudáveis, se apresentando com inflamação microscópica e citocinas pró-inflamatórias de natureza semelhante às da pele com lesões em cães com dermatite atópica (WOOD et al. 1996). Os achados histopatológicos na epiderme e derme de animais acometidos por dermatite atópica são aqueles reconhecidos em processos inflamatórios crônicos. De forma geral, essas alterações microscópicas foram descritas anteriormente como dermatite perivascular hiperplásica superficial (LOURES; CONCEIÇÃO, 2013). Dentre as alterações epidérmicas, a mais comumente encontrada é a hiperplasia difusa ou acantose, que se refere ao espessamento do estrato espinhoso devido ao maior número de queratinócitos. Também é descrita espongiose ou edema intercelular, assim como degeneração balonosa, na qual é observado o acúmulo de líquido em vacúolos no citoplasma dos queratinócitos. Em alguns casos, pode ser verificado um aumento da lâmina de queratina, hiperqueratose (LAVKER; MATOLTSY, 1970). Exocitose leucocitária ou infiltrado inflamatório através da epiderme, muitas vezes por células mononucleares como linfócitos, ou menos comumente por eosinófilos e neutrófilos, é bastante observada em pacientes atópicos, além de haver aumento do número de células de Langerhans 
em epiderme. Na derme é possível notar vasos sanguíneos dilatados, contudo a presença de edema é variável (MILLER; GRIFFIN; CAMPBELL, 2013).

As áreas predispostas às lesões da dermatite atópica são aquelas onde esta camada é mais fina, especulando-se que sejam suscetíveis à penetração de alérgenos. Tanto na espécie humana como na canina, o comprometimento da barreira cutânea está presente na pele eczematosa e na pele clinicamente não afetada de pacientes com dermatite atópica, o que favorece as infecções tegumentares de origem estafilocócica. Em humanos, Staphylococcus aureus é o agente causal mais comum dessas infecções. Em cães, Staphylococcus pseudintermedius tem sido tradicionalmente identificado como patógeno primário isolado da piodermite canina (HNILICA, 2012).

Os antígenos responsáveis por desencadear a resposta imune observada na DAC recebem o nome de alérgenos e estão no ambiente, promovendo uma hipersensibilidade do tipo I (OLIVRY, 2001; ALVES et al., 2018). Estes alérgenos são bolores, pólens, debris da epiderme humana, sementes de gramíneas, penas (figura 2) e a poeira doméstica (figura 1 ), a qual é constituída da mistura de resíduos de pele humana, pêlos de animais, ácaros, bolores, produtos de decomposição, partículas alimentares e substâncias inorgânicas (SCOTT; MILLER; GRIFFIN, 1996; 2002). Dentre os ácaros de poeira doméstica, destacam-se o Dermatophagoides farinae e o Dermatophagoides pteronyssinus (SCOTT; MiLLER; GRIFFIN, 1996) que habitam principalmente roupas de cama, travesseiros, carpetes, tapetes e outros materiais têxteis do domicílio, se alimentam de descamações do epitélio humano, fungos, bactérias, detritos orgânicos e secreções humanas.

Variações de umidade e temperatura do ar determinam o local onde vivem os ácaros. As diferenças regionais dos alérgenos em decorrência dos tipos de fauna (THOMPSON, 1997), e o estilo de vida de cada região (HILLIER; GRIFFIN, 2001) é algo importante a ser considerado. Além disso, os sinais clínicos iniciais podem manifestar-se em determinada época do ano, dividindo a DAC em sazonal e não sazonal. Nos Estados Unidos, cerca de $80 \%$ dos cães com atopia sazonal manifestam sinais clínicos iniciais no período da primavera ao outono e 20\% apresentam sintomatologia no inverno (SCOTT; MiLLER; GRIFFIN, 1996; 2001). Eventualmente, alguns pacientes desenvolvem a forma de atopia não sazonal, na qual o prurido ocorre durante todo o ano, porém, há agravamento dos sinais nos meses mais quentes (HILLIER, 2002). Nesses pacientes, a doença tende a se tornar mais crônica (HILLIER, 2002). Acredita-se que os cães geneticamente predispostos absorvem por via percutânea, inalam (SCOTT; MILLER; GRIFFIN, 1996; DEBOER, 2004) ou ingerem diversos alérgenos (WHITE, 1998). Em relação à absorção pela cútis, alguns autores inferem que há um aumento na penetração dos antígenos, devido a uma disfunção da barreira lipídica epiderme (SCOTT; MILLER; GRIFFIN, 1996; DEBOER, 2004). Isso ocorre por combinação deficiente de organelas lipídicas de superfície, existentes entre os espaços intercelulares, como é sugerido na atopia humana (OLIVRY; HILL, 2001). Dessa forma, há mudança na composição química da barreira lipídica epidérmica e um aumento na perda de água via transepidérmica.

Figura 1: Alérgenos não sazonais

\begin{tabular}{|c|}
\hline ALÉRGENOS NÃO SAZONAIS \\
\hline Ácaros e ácaros de Armazenamento \\
\hline Penas e Escamas \\
\hline Fungos \\
\hline Algodão, linha e lã \\
\hline Fonte: Os autores (2018).
\end{tabular}


Figura 2: Alérgenos sazonais

\begin{tabular}{|c|}
\hline ALÉRGENOS SAZONAIS \\
\hline Pólen de Gramíneas \\
\hline Pólen de Árvores \\
\hline Pólen de Plantas \\
\hline Pólen de Herbáceas e outros \\
\hline TFonte: Os autores (2018).
\end{tabular}

Após a prévia sensibilização cutânea, uma vez que o prurido se inicie, este conduz à injúria mecânica. Na presença de infecção bacteriana, os queratinócitos são ativados por produtos microbianos e derivados de fatores imunomediados, liberando citocinas e quimiocinas. Devido à hiper-reatividade Th2, há diminuição da atividade dos lipídios e peptídeos antimicrobianos (defensina e catelicidina), facilitando a penetração dos microrganismos tegumentares (ELIAS; WOOD; FEINGOLD, 1999). Uma vez que a sensibilização alérgica tenha ocorrido (OLIVRY et al., 2014, HILL; LAU; RYBNICEK, 2007) e a função de barreira tenha sido interrompida, ocorre uma piora progressiva desta, e ciclos repetitivos de sensibilização alérgica e inflamação se sucedem (MILLER; GRIFFIN; CAMPBELL, 2013).

Devido à alta incidência de distúrbios de hipersensibilidade, que alcança $15 \%$ entre os caninos, e por o diagnóstico da DAC representar 30\% dos atendimentos de dermatopatias (MILLER; GRIFFIN; CAMPBELL, 2013), faz-se necessário o melhor entendimento da patogenia e dos fatores envolvidos nessa doença. Somado a isso, quando se consegue fazer o diagnóstico preciso e precoce, melhor suporte é dado ao desenvolvimento de estratégias de tratamento e controle. Dessa forma, este estudo teve por objetivo principal analisar o padrão lesional e de prurido em cães das raças: Ihasas apso, yorkshire terrier, shih-tzu e pug, que são predispostas a DAC e com grande casuística em hospitais e clínicas veterinárias brasileiros com diversas queixas de alterações no sistema ototegumentar, principalmente o prurido frequente, com intuito de verificar se há aspecto fenotípico mais peculiar para cada raça.

\section{Materiais e métodos}

No presente trabalho foram utilizados vinte e três prontuários de cães da raça Ihasa apso (Figura 3), vinte e dois prontuários de cães da raça yorkshire terrier (Figura 4), quinze prontuários de cães da raça shih-tzu e sete prontuários de cães de raça pug e analisado o padrão lesional e de prurido destes. Os animais eram de ambos os sexos e já tinham sido diagnosticados anteriormente com dermatite atópica canina.

O diagnóstico foi baseado no Método de Hiller, pelo qual foi analisada a história e os sinais clínicos sugestivos de dermatite atópica (aparecimento das primeiras manifestações clínicas em idade inferior a três anos, sendo que o animal permanece a maior parte do tempo em ambiente interno, possui prurido responsivo a corticosteroides, piodermite de repetição, membros torácicos e pavilhões auriculares afetados, área dorso-lombar não afetada), foi realizada a citologia por fita adesiva, a citologia de cerúmen e tricograma, assim foi identificado e realizado o controle em alguns animais, que apresentavam piodermite, malasseziose, otite externa ou demodiciose. Então, os animais iniciaram o diagnóstico clínico por exclusão, com controle rigoroso de ectoparasitas, para exclusão de dermatite alérgica à picada de pulgas (DAPP), e então após a não resolução do quadro sintomático-lesional, foram 
submetidos à dieta de exclusão (caseira com proteína inédita ou comercial com proteína hidrolisada) por oito semanas. Só então, foram diagnosticados com DAC.

Estes cães foram atendidos no setor de dermatologia veterinária no Hospital Veterinário da Universidade Metodista de São Paulo, no período de janeiro de 2017 a abril de 2019.

Figura 3: Lhasa apso acometido por dermatite atópica com alopecia, hiperpigmentação e liquenificação generalizada

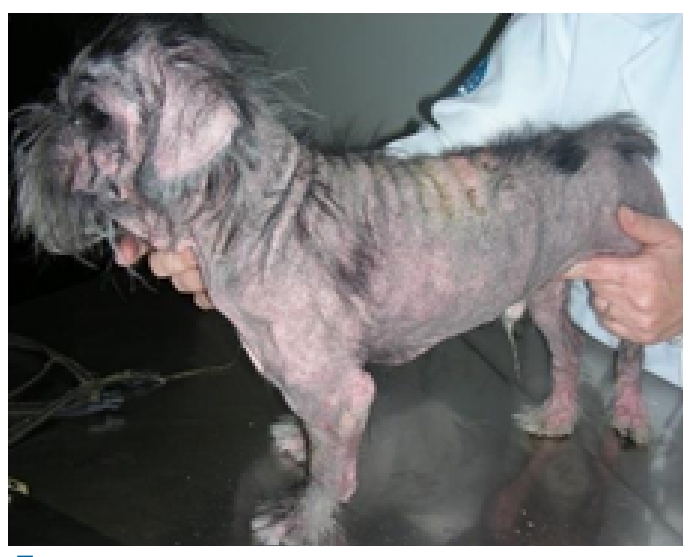

TFonte: SALZO (2015).
Figura 4: Yorkshire acometido por dermatite atópica com hiperpigmentação em flexuras de membro torácico

\section{Resultados}

Cães da raça lhasa apso obtiveram como resultado maior acometimento das regiões de falanges e interdígitos (96\%), face (83\%) e orelhas (74\%) e menor nas regiões de cabeça (4\%), esterno (4\%) e tronco (9\%), (Tabela 1; Figura 5); em cães da raça yorkshire terrier houve maior insulto nas regiões de falanges e interdígitos (91\%), orelhas (77\%) e tronco (64\%) e menor nas regiões de cabeça (5\%), jarrete (5\%) e perianal (9\%), (Tabela 2; Figura 6), em cães da raça shih-tzu obtiveram como resultado maior acometimento das regiões de falanges e interdígitos (100\%), orelhas (100\%) e face (80\%) menor nas regiões de abdômen (7\%), tórax (7\%) e genital (7\%), (Tabela 3; Figura 7). Em cães da raça pug notou-se maior acometimento das regiões de falanges e intedígitos (100\%), abdômen (86\%) e orelhas (86\%) e menor das regiões de cabeça (14\%), pescoço (14\%) e esterno (14\%), (Tabela 4; Figura 8).

Tabela 1: Porcentagem de acometimento por região em Ihasas apso atópicos atendidos no Hospital Veterinário da Universidade Metodista de São Paulo, entre janeiro de 2017 a abril de 2019

\begin{tabular}{|l|c|c|c|}
\hline \multicolumn{5}{|c|}{ LHASA APSO } \\
\hline Região & No de animais acometidos & No de animais total & Porcentagem \\
\hline Falanges e Interdígitos & 22 & 23 & $96 \%$ \\
\hline Face & 19 & 23 & $83 \%$ \\
\hline Orelhas & 17 & 23 & $74 \%$ \\
\hline Cervical & 10 & 23 & $43 \%$ \\
\hline Periocular & 10 & 23 & $43 \%$ \\
\hline Axilas & 9 & 23 & $39 \%$ \\
\hline Inguinal & 7 & 23 & $30 \%$ \\
\hline Abdômen & 6 & 23 & $26 \%$ \\
\hline Cauda & 5 & 23 & $22 \%$ \\
\hline
\end{tabular}




\begin{tabular}{|l|c|c|c|}
\hline Períneo & 4 & 23 & $17 \%$ \\
\hline Membros & 4 & 23 & $17 \%$ \\
\hline Dobra de membro & 4 & 23 & $17 \%$ \\
\hline Perianal & 3 & 23 & $13 \%$ \\
\hline Lombar & 3 & 23 & $13 \%$ \\
\hline Dorso lombar & 3 & 23 & $13 \%$ \\
\hline Flanco & 2 & 23 & $9 \%$ \\
\hline Genital & 2 & 23 & $9 \%$ \\
\hline Tronco & 2 & 23 & $9 \%$ \\
\hline Esterno & 1 & 23 & $4 \%$ \\
\hline Cabeça & 1 & 23 & $4 \%$ \\
\hline
\end{tabular}

TOs autores (2019).

Figura 5: Silhuetas de Ihasas apso atópicos (cada cor corresponde à porcentagem de animais afetados)

80 a $100 \%$

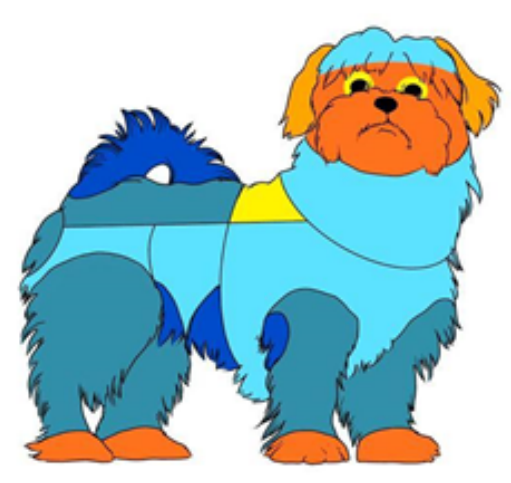

TOs autores (2019).

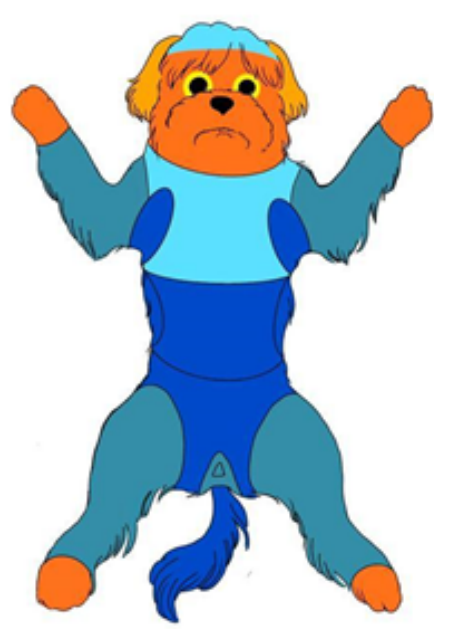

Tabela 2: Porcentagem de acometimento por região em yorkshires terrier atópicos atendidos no Hospital Veterinário da Universidade Metodista de São Paulo, entre janeiro de 2017 a abril de 2019

\begin{tabular}{|l|c|c|c|}
\hline \multicolumn{4}{|c|}{ YORKSHIRE TERRIER } \\
\hline Região & No de animais acometidos & No de animais total & Porcentagem \\
\hline Falanges e interdigitos & 20 & 22 & $91 \%$ \\
\hline Orelhas & 17 & 22 & $77 \%$ \\
\hline Tronco & 14 & 22 & $64 \%$ \\
\hline Face & 12 & 22 & $55 \%$ \\
\hline Periocular & 12 & 22 & $55 \%$ \\
\hline Cervical & 9 & 22 & $41 \%$ \\
\hline Abdômen & 9 & 22 & $41 \%$ \\
\hline Axilas & 8 & 22 & $36 \%$ \\
\hline Inguinal & 8 & 22 & $36 \%$ \\
\hline
\end{tabular}




\begin{tabular}{|l|c|c|c|}
\hline Esterno & 8 & 22 & $36 \%$ \\
\hline Membro & 7 & 22 & $32 \%$ \\
\hline Dorsal Lombar & 6 & 22 & $27 \%$ \\
\hline Cauda & 4 & 22 & $18 \%$ \\
\hline Períneo & 3 & 22 & $14 \%$ \\
\hline Dobra de membro & 3 & 22 & $14 \%$ \\
\hline Flanco & 2 & 22 & $9 \%$ \\
\hline Genital & 2 & 22 & $9 \%$ \\
\hline Perianal & 2 & 22 & $9 \%$ \\
\hline Jarrete & 1 & 22 & $5 \%$ \\
\hline Cabeça & 1 & 22 & $5 \%$ \\
\hline
\end{tabular}

Tos autores (2019).

Figura 6: Silhuetas de yorkshires atópicos (cada cor corresponde à porcentagem de animais afetados)

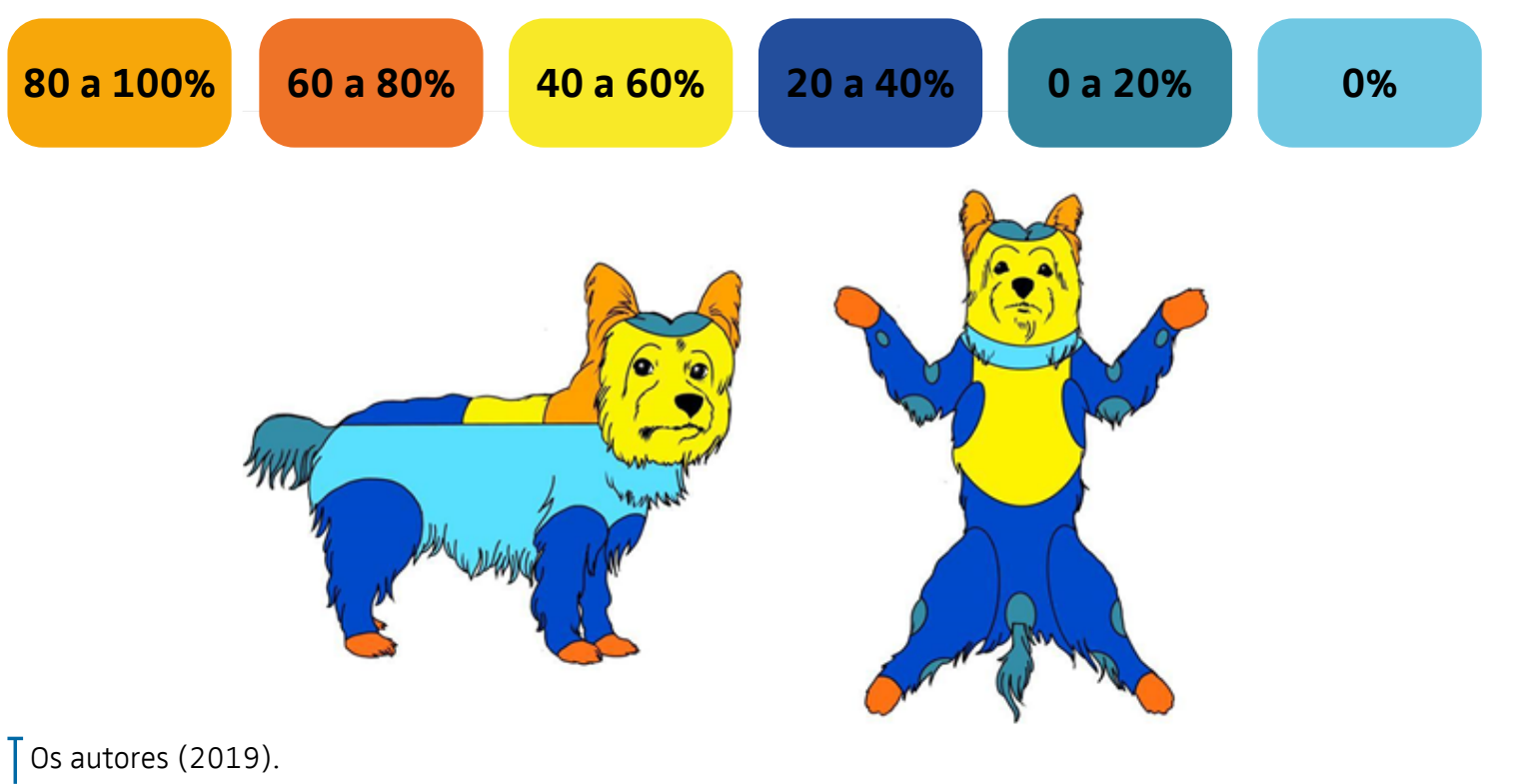

Tabela 3: Porcentagem de acometimento por região em shih-tzu atópicos atendidos no Hospital Veterinário da Universidade Metodista de São Paulo, entre janeiro de 2017 a abril de 2019

\begin{tabular}{|l|c|c|c|}
\hline \multicolumn{5}{|c|}{ SHIH-TZU } \\
\hline Região & No de animais acometidos & No de animais total & Porcentagem \\
\hline Orelhas & 15 & 15 & $100 \%$ \\
\hline Face & 12 & 15 & $80 \%$ \\
\hline Falanges e interdigitos & 15 & 15 & $100 \%$ \\
\hline Genital & 1 & 15 & $7 \%$ \\
\hline Cervical & 6 & 15 & $40 \%$ \\
\hline Periocular & 7 & 15 & $47 \%$ \\
\hline Axilas & 7 & 15 & $47 \%$ \\
\hline Inguinal & 5 & 15 & $33 \%$ \\
\hline Abdômen & 1 & 15 & $7 \%$ \\
\hline
\end{tabular}




\begin{tabular}{|l|c|c|c|}
\hline Tórax & 1 & 15 & $7 \%$ \\
\hline Membro & 9 & 15 & $60 \%$ \\
\hline Flanco & 3 & 15 & $20 \%$ \\
\hline Dobra de membro & 3 & 15 & $20 \%$ \\
\hline Esterno & 4 & 15 & $27 \%$ \\
\hline Tronco & 5 & 15 & $33 \%$ \\
\hline Cotovelo & 1 & 15 & $7 \%$ \\
\hline Joelho & 1 & 15 & $7 \%$ \\
\hline Períneo & 3 & 15 & $20 \%$ \\
\hline Periescrotal & 1 & 15 & $7 \%$ \\
\hline
\end{tabular}

Tos autores (2019).

Figura 7: Silhuetas de shih-tzu atópicos (cada cor corresponde à porcentagem de animais afetados)

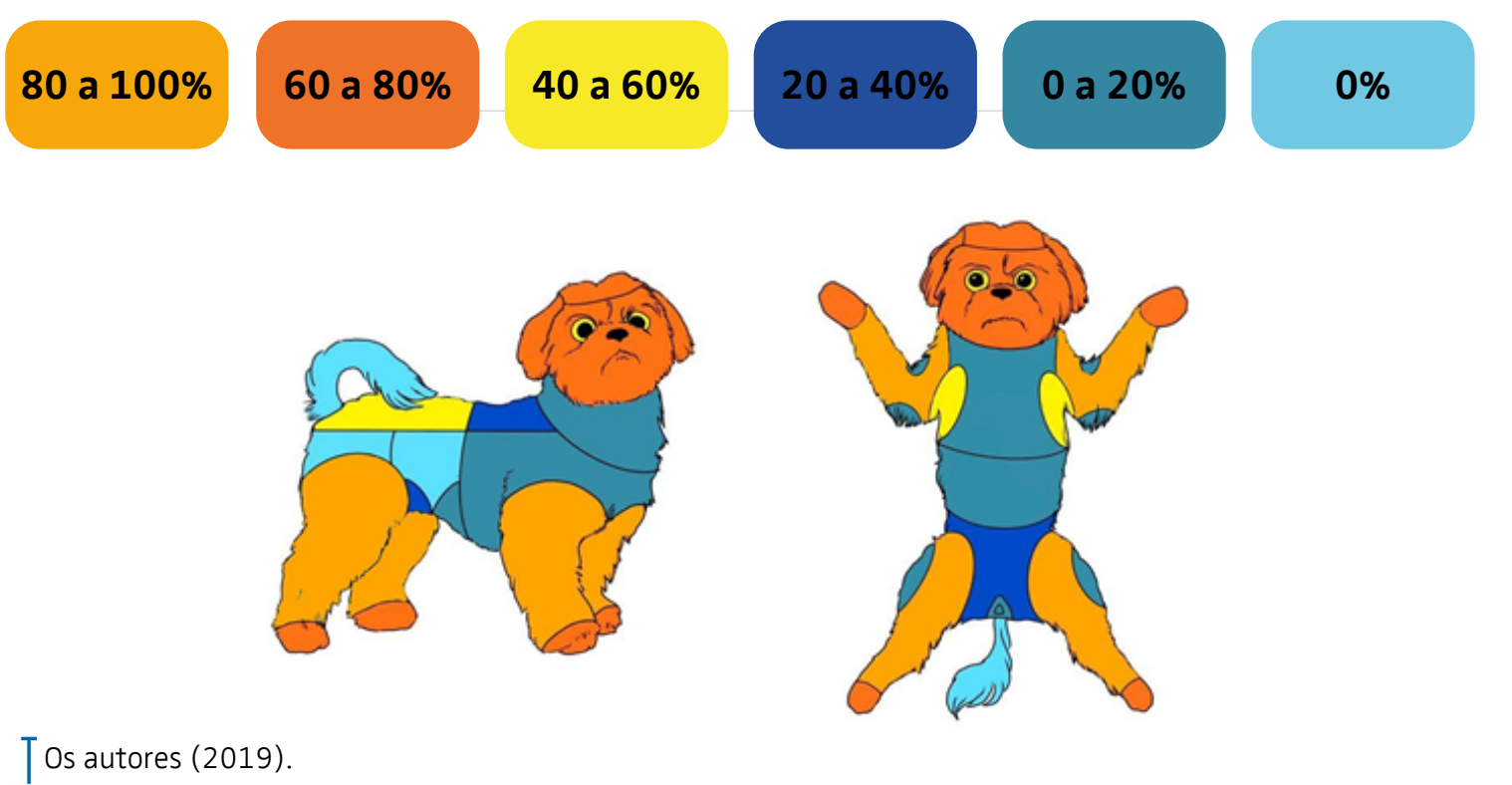

Tabela 4: Porcentagem de acometimento por região em pugs atópicos atendidos no Hospital Veterinário da Universidade Metodista de São Paulo, entre janeiro de 2017 a abril de 2019

\begin{tabular}{|l|c|c|c|}
\hline \multicolumn{5}{|c|}{ PUGS } \\
\hline Região & No de animais acometidos & No de animais total & Porcentagem \\
\hline Falanges e interdigitos & 7 & 7 & $100 \%$ \\
\hline Orelhas & 6 & 7 & $86 \%$ \\
\hline Abdômen & 6 & 7 & $86 \%$ \\
\hline Cervical & 5 & 7 & $71 \%$ \\
\hline Face & 4 & 7 & $57 \%$ \\
\hline Dobra de Membros & 3 & 7 & $43 \%$ \\
\hline Inguinal & 3 & 7 & $43 \%$ \\
\hline Tronco & 2 & 7 & $29 \%$ \\
\hline Cauda & 2 & 7 & $29 \%$ \\
\hline
\end{tabular}




\begin{tabular}{|l|c|c|c|}
\hline Periocular & 2 & 7 & $29 \%$ \\
\hline Pescoço & 1 & 7 & $14 \%$ \\
\hline Cabeça & 1 & 7 & $14 \%$ \\
\hline Esterno & 1 & 7 & $14 \%$ \\
\hline Tórax & 1 & 7 & $14 \%$ \\
\hline Cotovelo & 1 & 7 & $14 \%$ \\
\hline
\end{tabular}

TOs autores (2019).

Figura 8: Silhuetas de pugs atópicos (cada cor corresponde à porcentagem de animais afetados)

80 a $100 \%$

\section{0 a $80 \%$}

40 a $60 \%$

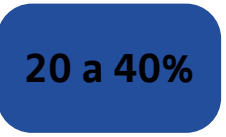

$0 \%$

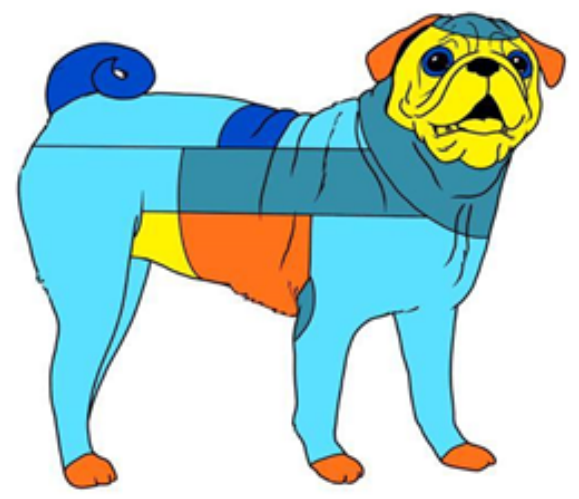

T Os autores (2020).

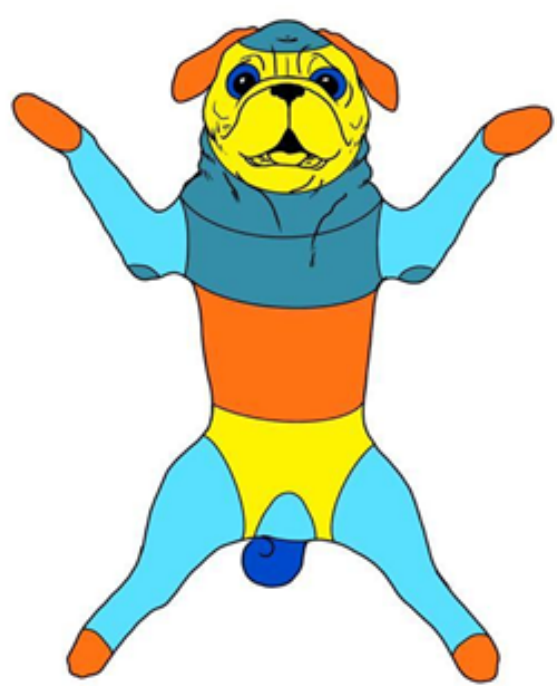

\section{Discussão}

Alguns autores relatam uma maior incidência de dermatite atópica em fêmeas, embora a predisposição sexual não tenha sido comprovada (SCOTT; MILLER; GRIFFIN, 1996, 2001). Isto foi observado neste estudo em Ihasas apso, onde havia quinze fêmeas e oito machos, yorkshire terriers, entre os quais havia treze fêmeas e oito machos, mas não foi observado em shih-tzus, pugs, dos quais o predomínio foi de machos, sendo que havia, entre os shih-tzus, oito machos e sete fêmeas, e entre os pugs, cinco machos e duas fêmeas.

Há relatos de que o início das manifestações clínicas da DAC ocorre entre seis meses a sete anos (SCOTT; MILLER; GRIFFIN, 2001) e que entre 70\% e 78\% dos cães diagnosticados com DAC, o quadro tem início antes dos animais completarem três anos de idade (FAVROT, 2009; SCOTT; MILLER, 2001), mas isso só foi observado em pugs com a idade média de três anos e a idade de acometimento variou de dez meses a seis anos, já na raça shih-tzu, a idade média foi de quatro anos e a idade de acometimento variou de quarenta dias a doze anos, já nos cães lhasa apso e yorkshire terrier podemos perceber que a idade média foi mais tardia, seis anos, sendo que em lhasa apso a idade de acometimento variou de oito meses a doze anos, e em cães da raça yorkshire terrier variou de um a quinze anos. 
Asáreas envolvidas na DAC costumam ser condutos auditivos, pavilhões auriculares, face (especialmente as regiões perioculares, perilabiais, mentonianas e o plano nasolabial) axilas, abdômen, virilhas, (KWOCHKA, 1998; OLIVRY; HILL, 2001) porção distal dos membros (superfícies dorsodigitais e interdigitais dorsal e ventral), áreas flexurais (flexuras carpianas, tíbio-társicas, as flexuras anticubitais e as flexuras poplíteas) e região perineal (SCOTT; MiLLER; GRIFFIN, 1996, 2001) e neste presente estudo isso foi comprovado, pois cães da raça Ihasa apso, yorkshire terrier, shih-tzu e pugs obtiveram como resultado maior acometimento das regiões citadas acima, principalmente das regiões de pavilhões auriculares, face, falanges e interdígitos.

No presente estudo, os dados observados foram bastante similares àqueles de um estudo já realizado anteriormente, o Breed-associated phenotypes in canine atopic dermatitis, apresentado no Congresso da ECVD-ESVD, na Itália, em 2010, onde se notou que os animais das raças boxer, dálmata, bulldog francês, pastor alemão, golden retriever dourado, jack russell terrier, labrador retriever, shar-pei e terrier branco das montanhas ocidentais não obtiveram um padrão lesional definido pelo fenótipo da raça, pois apresentaram lesões de amplas variações, apesar da diferença genética.

\section{Considerações finais}

Conclui-se que ao se comparar o padrão fenotípico de cães das raças Ihasa apso, yorkshire terrier, shih-tzu e pug, não houve diferenças significativas em termos de distribuição lesional, a despeito da potencial diferença genética. Contudo, estudos com número maior de cães são necessários para que os resultados da avaliação do padrão fenotípico sejam mais fidedignos. 8

\section{Referências}

ALVES, B. et al. Dermatite atópica canina: estudo de caso. PUBVET, v. 12, n. 8, p. 1-6, 2018. DOI: http://dx.doi.org/0.31533/pubvet.v12n8a154.1-6. Disponível em: http://www.pubvet. com.br/uploads/e8a84bff9879048d7ffd64057c59717a.pdf. Acesso em: 23 de mai. 2019.

BILSBOROUGH, J. et al. IL-31 is associated with cutaneous lymphocyte antigenpositive skin homing T cells in patients with atopic dermatitis. Journal of Allergy and Clinical Immunology, v.117, n.2, p. 418-425, 2006. DOl: http://dx.doi.org/10.1016/j.jaci.2005.10.046. Disponível em: https://scihub. wikicn.top/10.1016/j.jaci.2005.10.046. Acesso em: 23 de mai. 2019.

CHREN, M. M. et al. Skindex, a quality-of-life measure for patients with skin disease: reliability, validity, and responsiveness. Journal of Investigative Dermatology, v.107, n. 5, p.707-713, 1996. DOl: http://dx.doi. org/10.1111/1523-1747.ep12365600. Disponivel em: https://scihub.wikicn.top/10.1111/1523-1747. ep12365600. Acesso em: 23 de mai. 2019.

DEBOER, D. J. Canine atopic dermatitis: new targets, new therapies. The Jounal of Nutrition, v. 134, n. 8, p. 2056S-2061S, 2004. DOI: https://doi.org/10.1093/jn/134.8.2056S. Disponível em: https:// academic.oup.com/jn/article/134/8/2056S/4688875. Acesso em: 24 mar. 2021.

ELIAS, P. M.; WOOD, L. C.; FEINGOLD, K. R. Epidermal pathogenesis of inflammatory dermatoses. American Contact Dermatitis Society, v.10, p.119-126, 1999.

FAVROT, C. Clinical signs and diagnosis of canine atopic dermatitis. European Journal of Companion Animal Practice, v. 19, p. 219-222, 2009.

FAVROT, C. et al. A prospective study on the clinical features of chronic canine atopic dermatitis and its diagnosis. Veterinary Dermatology, v. 21, n. 1, p. 23-31, 2010. DOI: https://doi.org/10.1111/ j.1365-3164.2009.00758.x. 
GRIFFIN, C. E.; DEBOER, D. J. The ACVD task force on canine atopic dermatitis (XIV): clinical manifestations of canine atopic dermatitis. Veterinary Immunology and Immunopathology, v. 81, n. 3-4, p. 255-269, 2001. DOI: https://doi.org/10.1016/S0165-2427(01)00346-4.

HALLIWELL, R. Revised nomenclature for veterinaryallergy. Veterinary Immunology and Immunopathology, v.114, n. 3-4, p. 2007-2008, 2006. DOl: https://doi.org/10.1016/j.vetimm.2006.08.013.

HILL, P.B.; LAU, P.; RYBNICEK, J. Development of an owner-assessed scale to measure the severity of pruritus in dogs. Veterinary Dermatology. n.18, n. 5, p.301-308, 2007. DOl: https://doi.org/10.1111/j.13653164.2007.00616.x. Disponível em: https://scihub.wikicn.top/10.1111/j.1365-3164.2007.00616.x. Acesso em: 15 de out. 2019.

HILLIER, A.; DEBOER, D. J. The ACVD task force on canine atopic dermatitis (xVII): intradermal testing. Veterinary Immunology and Immunopathology, v. 81, n. 3-4, p. 289-304, 2001. DOI: https://doi. org/10.1016/S0165-2427(01)00313-0.

HILLIER, A.; GRIFFIN, C. The ACVD task force on canine atopic dermatitis (I): incidence and prevalence. Veterinary Immunology and Immunopathology, v. 81, n. 3-4. p. 147-151, 2001. DOl: https://doi. org/10.1016/S0165-2427(01)00296-3.

HNILICA, K. A. Doenças de pele bacterianas. In: HNILICA, K. ; PATTERSON, A.P. Dermatologia de pequenos animais: atlas colorido e guia terapêutico. 3. ed. Rio de Janeiro: Elsevier, Cap. 3, p. 41-47, 2012.

LAVKER, R. M.; MATOLTSY, A. G. Formação de células com tensão: o destino das células e produtos de diferenciação no epitélio ruminal. Journal of Cell Biology, n.44, p.501-512, 1970.

LOURES, F. H.; CONCEIÇÃO, L. G. Biópsia de pele: quando, onde e como. Maximizando benefícios. In: JÚNIO, A. P. et al. Cadernos Técnicos de Veterinária e Zootecnia: Dermatologia em Cães e Gatos. Belo Horizonte: FEPMVZ, Editora, no 71, 2013, 144p.

MAJESKI, C. J. et al. Itch Severity Scale: a self-report instrument for the measurement of pruritus severity. British Journal of Dermatology. v.156, n. 4, p.667-673, 2007. DOI: https://doi.org/10.1111/j.13652133.2006.07736.x.

MARSELLA, R.; SAMUELSON, D. Unravelling the skin barrier: a new paradigm for atopic dermatitis and house dust mites. Veterinary Dermatology, v. 20, n. 5-6, p. 533- 540, 2009. DOI: https://doi. org/10.1111/j.1365-3164.2009.00809.x. Disponível em: https://scihub.wikicn.top/10.1111/j.13653164.2009.00809.x. Acesso em: 27 de jul. 2019.

MILLER, W.; GRIFFIN, C.; CAMPBELL, K. Muller and Kirk's Small Animal Dermatology. 7. ed. St. Louis: Elsiever Health Sciences, 2013, 948 p.

NODTVEDT, A. et al. Incidence of and risk factors for atopic dermatitis in a Swedish population of insured dogs. Veterinary Record. v. 159, n. 8, p. 241-246, ago. 2006. DOl: https://doi.org/10.1136/vr.159.8.241.

OLIVRY, T.; HILL, P. B. The ACVD task force on canine atopic dermatitis (VIII): is the epidermal lipid barrier defective?. Veterinary Immunology and Immunopathology. v. 81, n. 3-4, p. 215-218, 2001. DOI: https://doi.org/10.1016/S0165-2427(01)00301-4.

OLIVRY, T.; HILL, P. B. The ACVD task force on canine atopic dermatitis (XVII): histopathology of skin lesions. Veterinary Immunology and Immunopathology, v.81,n.3-4, p.305-309,2001.DOl:https://doi.org/10.1016/ S0165-2427(01)00305-1. Disponível em: https://scihub.wikicn.top/10.1016/s0165-2427(01)00305-1. Acesso em: 15 de out. 2019.

OLIVRY, T. et al. Treatment of canine atopic dermatitis: 2010 clinical practice guidelines from the International Task Force on Canine Atopic Dermatitis Veterinary Dermatology, v. 21, n. 3, p. 233-248, 2010. DOI: https://doi.org/10.1111/j.1365-3164.2010.00889.x. Disponível em: https://scihub.wikicn. top/10.1111/j.1365-3164.2010.00889.x. Acesso em: 12 de abril. 2019. 
OLIVRY, T. et al. Validation of the canine atopic dermatitis extent and Severity index (CADESI) - 4, a simplified severity scale for assessing skin lesions of atopic dermatitis in dogs. Veterinary Dermatology, v.25, n. 2, p.77-e25, 2014. DOl: https://doi.org/10.1111/vde.12107.

SCOTT, D.W.; MILLER, W.H.; GRIFFIN, C.E. Muller \& Kirk's Dermatologia de Pequenos Animais. 5.ed. Rio de Janeiro: Interlivros, 1996, 1130p.

SCOTT, D. W.; MILLER JUNIOR, W. H.; GRIFFIN, G. E. Muller \& Kirk's Small Animal Dermatology, 6. ed. Philadelphia: W. B. Saunders Company, 6.ed., 2001, 1528p. DOl: https://doi.org/10.1016/B978-07216-7618-0.X5001-9.

SOLOMON, S. E. B.; FARIAS, M. R. de; PIMPÃO, C. T. Dermatite atópica canina: Fisiopatologia e Diagnóstico. Revista Acadêmica de Ciências Agrárias Ambiental. v. 10, n. 1, p. 21-28, jan./mar. 2012. DOI: https://doi.org/10.13140/RG.2.1.4843.3122. Disponível em: https://periodicos.pucpr.br/index.php/ cienciaanimal/article/viewFile/12068/11399. Acesso em: 24 de mai. 2019.

SOUZA, C. A.; MARSELLA, R. The ACVD task force on canine atopic dermatitis (II): genetic factors. Veterinary Immunology and Immunopathology, v. 81, n. 3-4, p. 153-157, 2001. DOI: http://dx.doi. org/10.1016/S0165-2427(01)00297-5. Disponível em: https://scihub.wikicn.top/10.1016/s01652427(01)00297-5. Acesso em: 25 de nov. 2019.

THOMPSON, J. P. Moléstias imunológicas. In: ETTINGER, S. J.; FELDMAN, E. C. Tratado de Medicina Interna Veterinária. 4. ed. São Paulo: Manole, v. 2, p. 2766-2802, 1997.

WILHEM, S.; KOVALIK, M.;FAVROT, C. Breed-associated phenotypes in canine atopic dermatitis. Veterinary Dermatology, v.22, n.2, p.143-149, 2011. DOI: https://doi.org/10.1111/j.1365-3164.2010.00925.x.

WHITE, P. D. Atopia. In: BICHARD, S. J.; SHERDING, R. G. Manual Saunders: clínica de pequenos animais. São Paulo: Roca, p. 343-351, 1998.

WHITE, M.I; JENKINSON, D. M., LLOYD, D. H. The effect of washing on the thickness of the stratum corneum in normal and atopic individuals. British Journal of Dermatology, v.116, n. 4, p.525-530, 1987. DOI: https://doi.org/10.1111/j.1365-2133.1987.tb05873.x.

WOOD, S. H. et al. Gene expression in canine atopic dermatitis and correlation with clinical severity scores. Journal of Dermatological Science, v.55, n.1, p.27-33, 2009. DOI: https://doi.org/10.1016/j. jdermsci.2009.03.005. Disponível em: https://scihub.wikicn.top/10.1016/j.jdermsci.2009.03.005. Acesso em: 18 de jun. 2019. 